\title{
Degradabilidade ruminal e fracionamento de carboidratos de silagens de grama estrela (Cynodon nlemfuensis vanderyst.) com diferentes aditivos
}

\section{Ruminal degradability and carbohydrate fractioning of stargrass silages (Cynodon nlemfuensis vanderyst.) with different additives}

\author{
Valter Harry Bumbieris Junior ${ }^{1 *}$; Fábio Jacobs Dias ${ }^{1}$; Ricardo Kazama ${ }^{1}$; Domênico \\ Sales Rocha de Arruda ${ }^{1}$; Clóves Cabreira Jobim²*; Maria da Graça Morais ${ }^{3}$
}

Resumo

Objetivou-se com o estudo avaliar o efeito de aditivo enzimo-bacteriano e de uréia sobre a degradabilidade ruminal e o fracionamento de carboidratos em silagens de grama estrela. Foram avaliadas silagens sem aditivo (SGE) e com aplicação de aditivo enzimo-bacteriano (SGE150 e SE300, respectivamente 150 e 300 $\mathrm{g}$ aditivo/tonelada) e uréia (SGEU, $10 \mathrm{~kg} /$ tonelada). Para o ensaio de degradabilidade foram utilizados três bois da raça Holandesa distribuídos em blocos casualizados. A degradabilidade efetiva (DE) da MS e da FDN foram maiores para o tratamento SGE300 em todas as taxas de passagem. Para a DE da PB houve diferença $(\mathrm{P}<0,05)$ para o tratamento SGEU. Os carboidratos totais $(\mathrm{CHT})$ tiveram os maiores valores para o tratamento SGE, enquanto que, para as frações $\mathrm{A}+\mathrm{B} 1$ e $\mathrm{B} 2$ não houve efeito significativo entre os tratamentos. Para a fração $\mathrm{C}$ os menores valores foram para os tratamentos com inoculante. Conclui-se que a aplicação do inoculante ou uréia não melhoraram a degradabilidade potencial (DP) das silagens de grama estrela em relação ao tratamento isento da aplicação de inoculante.

Palavras-chave: Fibra, inoculante, nutrientes, rúmen, uréia

\begin{abstract}
It was aimed to evaluate in this trial the effect of additive and urea supplies on ruminal degradabilty and carbohydrates fractioning of stargrass silages. There were evaluated silage without additive (SGE), silage with enzymatic-bacterial additive (SGE150 and SGE300 respectively, 150 and $300 \mathrm{~g}$ of additive/ton of silage) and silage with urea (SGEU, $10 \mathrm{~kg} / \mathrm{ton}$ ). Three Holstein steers were used in blocks randomizeds design for ruminal degradability assay. The effective degradability (ED) of DM and NDF were higher $(\mathrm{P}<0.05)$ for SGE300 treatment for all flow rates. There was difference $(\mathrm{P}<0.05)$ for $\mathrm{ED}$ of $\mathrm{CP}$ in silage supplied with urea. Total carbohydrates presented the highest values for no additive treatment, while $\mathrm{A}+\mathrm{B} 1$ and B2 fractions didn't differ $(\mathrm{P}>0.05)$ among treatments. Silages with additive presented the lowest values $(\mathrm{P}<0.05)$ of $\mathrm{C}$ fraction. It was concluded that additive or urea supply in stargrass silages didn't improve the potential degradability (PD) when compared to the silage without additive.

Key words: Fiber, inoculant, nutrients, rúmen, urea
\end{abstract}

1* Acadêmicos do Programa de Pós-Graduação em Zootecnia - Universidade Estadual de Maringá (PPZ/UEM)-PR. Nível : Doutorado. e:mail: dudabumbieris@hotmail.com

2* Departamento de Zootecnia, Programa de Pós-Graduação em Zootecnia - Universidade Estadual de Maringá (PPZ-UEM)-PR, Pesquisador do CNPq. e:mail:ccjobim@uem.br

3 Departamento de Zootecnia, Programa de Pós-Graduação em Ciência Animal - Universidade Federal do Mato Grosso do Sul (UFMS)-MS.

* Autor para correspondência 


\section{Introdução}

O Brasil tem se destacado como grande produtor de carne e leite em nível mundial, sendo a grande maioria desses animais criados em pasto, tendo a necessidade de alimento de qualidade durante todo o ano, fato imprescindível para manter o desempenho na produção. Diante de tal fato, há a necessidade da utilização de tecnologias de conservação de forragens como mantenedora de alimentos de melhor qualidade em épocas de restrição, em razão da estacionalidade de produção de forragens.

Nesse contexto, o gênero Cynodon tem conseguido uma boa abrangência no território brasileiro, sendo muito explorado para pastejo e também como feno. São ainda poucas as pesquisas desenvolvidas com a finalidade de ensilagem desse gênero, tornando necessário mais estudos, visto que a utilização desse gênero como silagem tem despertado o interesse de produtores rurais, principalmente como alternativa ao manejo de campos de feno, quando as condições climáticas tornam-se adversas ao processo de fenação.

Portanto, o conhecimento sobre o fornecimento de nutrientes das forragens ao animal torna-se importante, visto que, ao conhecer o que a forrageira está suprindo em nutrientes, tem-se a possibilidade de adequação do balanço dos nutrientes para crescimento microbiano e para a produção do animal, procurando a maximização da eficiência energética e protéica (NUTRITIONAL RESEARCH COUNCIL, 1996).

Também a determinação da extensão e da taxa de degradação dos nutrientes é importante, pois determina o suprimento de energia para os microrganismos do rúmen, bem como a disponibilidade de nitrogênio para síntese de proteína microbiana (GARCIA et al., 2003). Algumas espécies apresentam déficit no conteúdo de nitrogênio para atendimento das exigências dos animais, em virtude da própria estrutura morfológica e metabolismo que apresentam.

Segundo Minson (1990), as gramíneas de clima tropical possuem teores de proteína bruta inferiores ao das espécies de clima temperado. Grande parte destas gramíneas apresenta teores de proteína bruta que podem ser insatisfatórios para o atendimento das exigências de alguns níveis de produção de leite e crescimento.

O conhecimento das frações carboidrato e proteína são também muito importantes no aspecto nutricional, visto que, são parte fundamental no desenvolvimento de dietas balanceadas.

As forrageiras de clima tropical apresentam algumas limitações de natureza nutritiva que se refletem negativamente sobre a produção animal, entretanto, a partir de um conhecimento mais aprofundado destas limitações e das suas reais implicações na produção animal, pode-se propor alternativas que produzam melhorias nos sistemas produtivos, incrementando a produtividade animal. Alguns aditivos são utilizados com intuito de melhorar o padrão de fermentação das silagens, outros a digestibilidade, e também o teor de proteína bruta.

Os inoculantes biológicos para gramíneas tropicais têm tido boa aceitação no mercado, em virtude da facilidade de aplicação e pela ausência de toxicidade. O intuito da utilização de aditivos enzimo-bacterianos é aumentar a população de bactérias ácido lático e, pela ação das enzimas promover a ruptura parcial de parede celular melhorando a qualidade de fermentação e, conseqüentemente, melhor preservação da qualidade da forragem (REIS; BERNARDES; SIQUEIRA, 2004).

O presente trabalho teve como objetivo avaliar o efeito de aditivo enzimo-bacteriano e da uréia sobre a degradabilidade ruminal e o fracionamento de carboidratos em silagens de grama estrela (Cynodon nlemfuensis Vanderyst). 


\section{Material e Métodos}

O experimento foi realizado no setor de Bovinocultura de Corte da Fazenda Experimental de Iguatemi e no Laboratório de Análise de Alimentos e Nutrição Animal (LANA), ambos pertencentes ao Departamento de Zootecnia da Universidade Estadual de Maringá.

Os tratamentos testados foram:

SGE = Silagem de grama estrela (Cynodon nlemfuensis Vanderyst) sem uso de aditivo;

SGE150 = Silagem de grama estrela (Cynodon nlemfuensis Vanderyst) com uso de aditivo enzimobacteriano comercial Katec $®$ Bacto Silo C. Tropical (150 g/tonelada de matéria natural);

SGE300 = Silagem de grama estrela (Cynodon nlemfuensis Vanderyst) com uso de aditivo enzimobacteriano comercial Katec $®$ Bacto Silo C. Tropical (300 g/tonelada de matéria natural);

SGEU $=$ Silagem de grama estrela (Cynodon nlemfuensis Vanderyst) com uréia (10 kg/tonelada de matéria natural).

As silagens foram confeccionadas em silos experimentais (manilhas de cimento de 1,20 m de largura x 1,0 m de altura) com capacidade para cerca de $1000 \mathrm{~kg}$ de silagem. A área de pasto de grama estrela (estádio vegetativo) utilizada para confecção das silagens apresentava relvado com cerca de 40 $\mathrm{cm}$, após cerca de 70 dias de crescimento. A forragem foi colhida com ensiladeira modelo JF90 e no momento da ensilagem o inoculante foi aspergido com uma bomba pulverizadora de maneira homogênea no material a ser ensilado.

O inoculante utilizado (Bacto Silo C. Tropical Katec $®)$ é composto por um complexo bacteriano termófilo em alta concentração especialmente adaptado as condições tropicais e um complexo enzimático especifico para capins tropicais. As garantias por quilograma do produto são: umidade (max) 8\%, dextrose $75 \%$, complexo enzimático 10 $\mathrm{g}$, Lactobacillus spp $240 \mathrm{~g}$.
A aplicação da uréia foi de maneira manual, distribuindo de forma que se observasse homogeneidade da mesma com o material a ser compactado. Imediatamente depois de cheios, os silos foram vedados adequadamente com uso de lona preta.

Foram utilizados para o experimento de degradabilidade três bovinos da raça Holandesa, com peso vivo médio de $480 \mathrm{Kg}$, portadores de cânula ruminal. Os animais foram adaptados à alimentação durante cinco dias antes da incubação ruminal, sendo alimentados duas vezes ao dia, às 8:00 e 16:00 h. A dieta era composta pelas silagens de grama estrela mais adição de concentrado à base de milho e farelo de soja.

As amostras das silagens foram submetidas à secagem em estufa de ventilação forçada, a $55^{\circ} \mathrm{C}$ por 72 horas e logo após foram moídas em peneira de $5 \mathrm{~mm}$ para posterior utilização.

A degradabilidade ruminal da matéria seca, da proteína bruta e da fibra em detergente neutro das silagens incubadas, e suas respectivas taxas de degradação foram estimadas pela técnica in situ do saco de náilon. Sacos de náilon (ANKOM-BAR DIAMOND, INC., Parma Idaho - USA) foram utilizados para incubação ruminal. As dimensões dos sacos eram de $10 \mathrm{~cm}$ x $20 \mathrm{~cm}$, com diâmetro de poros de 53 micra. Aproximadamente $7 \mathrm{~g}$ de amostra (base MS) foram acondicionadas em cada saco, fechando-os e atando-os com elástico de borracha. Nos dias de incubação, os sacos foram presos a uma barra cilíndrica de ferro inoxidável (600 g) suspensa por um fio de náilon de $60 \mathrm{~cm}$ de comprimento.

Os tempos de incubação empregados tiveram duração de 0, 6, 12, 24, 48, 72 e 96 horas. Os sacos foram incubados todos numa mesma hora, sendo retirados nos tempos determinados. Após a remoção, os sacos foram lavados em água corrente e posteriormente em máquina de lavar, em cinco ciclos por $10 \mathrm{~min}$. As amostras do tempo zero hora foram lavadas em água corrente.

Após serem lavados, os sacos foram submetidos à secagem em estufa de ventilação forçada, a $55^{\circ} \mathrm{C}$ 
por 72 horas. A porcentagem de desaparecimento da matéria seca, proteína bruta e fibra em detergente neutro por tempo de incubação, foi calculada pela proporção de alimento que restou nos sacos após a incubação ruminal. A partir dos valores obtidos foi calculado a curva de desaparecimento das frações MS, PB e FDN.

A degradabilidade da matéria seca e dos demais nutrientes foi calculada através da equação descrita por Mehrez e Orskov (1977),

$$
\mathrm{p}=\mathrm{a}+\mathrm{b}^{*}\left(1-\mathrm{e}^{-\mathrm{c} * t}\right) .
$$

Onde:

$\mathrm{p}=$ degradação potencial no tempo t;

$\mathrm{a}=$ porção prontamente degradável no rúmen;

$\mathrm{b}=$ fração insolúvel, mas potencialmente degradável;

$\mathrm{c}=$ taxa constante de degradabilidade da fração b;

$\mathrm{t}=$ tempo de incubação;

$a+b \leq 100$

Os parâmetros não-lineares a, b e c foram estimados pelos procedimentos iterativos de quadrados mínimos (iterative least-squares). A degradabilidade efetiva da matéria seca, proteína bruta e fibra em detergente neutro foi calculada através da equação descrita por Orskov e McDonald (1979):

Degradabilidade efetiva $=a+(b * c) /(c+k)$,

Onde: $\mathrm{k}$ = taxa estimada da passagem de sólidos no rúmen;

Demais parâmetros foram descritos na equação anterior.

Como não foi determinada a taxa de passagem real, a degradabilidade efetiva para cada alimento foi estimada com taxas de passagem de sólidos de $2 \% / \mathrm{h}, 5 \% / \mathrm{h}$ e $8 \% / \mathrm{h}$ que são atribuídas, respectivamente, ao nível baixo, médio e alto de ingestão alimentar (AGRICULTURAL AND FOOD RESEACH COUNCIL, 1993).

O dados foram arranjados em blocos casualizados, com três repetições para cada tratamento. Os resultados obtidos foram submetidos à análise de variância e comparados utilizando-se o teste Tukey ao nível de 5\% de significância, utilizando-se o sistema para análises estatísticas e genéticas SAEG (UNIVERSIDADE FEDERAL DE VIÇOSA, 1997).

O modelo matemático utilizado para a análise de variância foi:

$$
Y i j k=m+A i+T j+e i j,
$$

onde:

$\mathrm{m}=$ média dos tratamentos;

$\mathrm{Ai}=$ efeito do animal $\mathrm{i}$, variando de 1 a 3 ;

$\mathrm{Tj}=$ efeito do tratamento $\mathrm{j}$, variando de 1 a 4 ;

eij = erro aleatório.

Os valores de carboidratos totais (CHT) foram calculados pela equação;

$$
\mathrm{CHT}=\mathrm{MO}-(\mathrm{EE}+\mathrm{PB}) .
$$

Também foi determinado o fracionamento dos carboidratos segundo Sniffen et al, (1992).

A fração $\mathrm{C}$ foi determinada pela fórmula $\mathrm{C}=(100$ x FDN (\%MS) x 0,01 x LIGNINA (\%FDN) x 2,4/ CHT (\%MS)), sendo CHT, carboidratos totais.

A fração B2 foi obtida pela equação $\mathrm{B} 2=100 \mathrm{x}$ $((\mathrm{FDN}(\% \mathrm{MS})-\mathrm{PIDN}(\% \mathrm{~PB})$ x $0,01 \times \mathrm{PB}(\% \mathrm{MS}))$ - FDN(\%MS) x 0,01 x LIGNINA(\%FDN) x 2,4)))/ $\mathrm{CHT}(\% \mathrm{MS})$, onde PIDN é proteína insolúvel em detergente neutro. A fração $\mathrm{A}+\mathrm{B} 1$ foi determinada pela diferença entre $100-(C+B 2)$.

O modelo matemático empregado para o fracionamento dos carboidratos foi o seguinte:

$$
Y_{i j}=m+T_{i}+e_{i j}
$$

Onde: $\mathrm{m}=$ média dos tratamentos;

$\mathrm{T}_{\mathrm{i}}=$ efeito do tratamento $i$, variando de $1 \mathrm{a} 4$;

$\mathrm{e}_{\mathrm{ij}}=$ erro aleatório associado a cada observação i.[

Os resultados obtidos foram submetidos à análise de variância e comparados utilizando-se o teste Tukey ao nível de 5\% de significância.

Os teores de matéria seca (MS), proteína bruta (PB), foram obtidos segundo Association Of Official 
Analitical Chemists (1985). A determinação da Fibra em Detergente Neutro (FDN), Fibra em Detergente Ácido (FDA), Nitrogênio Indigestível em Detergente Neutro (NIDN) e Lignina foram obtidos de acordo com Van Soest, Robertson e Lewis (1991).

\section{Resultados e Discussão}

A Tabela 1 mostra os valores para composição químico-bromatológica das silagens de grama estrela (Cynodon nlemfuensis Vanderyst).

Tabela 1. Composição químico-bromatológica (\%MS) da silagem de grama estrela (Cynodon nlemfuensis Vanderyst) com uso de aditivos.

\begin{tabular}{lcccc}
\hline & \multicolumn{4}{c}{ Tratamentos } \\
\hline & SGE & SGE150 & SGE300 & SGEU \\
\hline MS (\%) & 30,3 & 33,8 & 30,7 & 35,9 \\
PB (\%) & 8,9 & 10,0 & 8,3 & 14,3 \\
FDN (\%) & 79,5 & 78,9 & 80,1 & 79,5 \\
FDA (\%) & 43,9 & 43,9 & 46,7 & 46,9 \\
LIG (\%) & 8,2 & 8,0 & 7,8 & 8,8 \\
\hline
\end{tabular}

$\mathrm{SGE}=$ Silagem de grama estrela sem uso de aditivo SGE150 = Silagem de grama estrela com aditivo Katec $®$ Bacto Silo C. Tropical ( $150 \mathrm{~g}$ aditivo/ton de matéria natural); SGE300 = Silagem de grama estrela com aditivo Katec $($ Bacto Silo C. Tropical (300g aditivo/ ton de matéria natural); SGEU = Silagem de grama estrela com uréia (10 kg/tonelada matéria natural).

O desaparecimento ruminal da matéria seca (MS), Proteína Bruta (PB) e Fibra em Detergente Neutro (FDN) para as silagens de grama estrela estudadas são apresentadas nas Tabelas 2,3 e 4 respectivamente.

As silagens SGE300, SGE150 e SGEU tiveram os maiores valores $(\mathrm{P}>0,05)$ para a fração solúvel (a) da MS e, apesar de não significativos, os tratamentos SGE300 E SGEU apresentaram os maiores valores para a fração potencialmente degradável (b). A maior fração (a) dos tratamentos SGE300, SGE150 e SGEU em relação a SGE provavelmente são advindos da ação direta das enzimas presentes no inoculante e da uréia, confirmando a hipótese de maior fornecimento de substrato para a fermentação. Quanto a taxa de degradação, não foram observados valores significativamente diferentes $(\mathrm{P}>0,05)$.

Tabela 2. Fração solúvel (a) e insolúvel potencialmente degradável (b), taxa de degradação (c), degradabilidade potencial (DP) e degradabilidade efetiva (DE) da Matéria seca, das silagens para as taxas de passagem de $2 \% / \mathrm{h}, 5 \% / \mathrm{h}$ e $8 \% / \mathrm{h}$.

\begin{tabular}{lccccc}
\hline & \multicolumn{5}{c}{ Tratamentos } \\
\cline { 2 - 6 } \multicolumn{1}{c}{ Parâmetros } & SGE & SGE150 & SGE300 & SGEU & CV\% \\
\hline & \multicolumn{7}{c}{ Matéria Seca } & & \\
\hline $\mathrm{a}$ & $15,0 \mathrm{~b}$ & $18,6 \mathrm{a}$ & $19,1 \mathrm{a}$ & $16,8 \mathrm{ab}$ & 5,9 \\
$\mathrm{~b}$ & $41,2 \mathrm{a}$ & $46,7 \mathrm{a}$ & $53,6 \mathrm{a}$ & $51,6 \mathrm{a}$ & 16,3 \\
$\mathrm{c}$ & $0,02 \mathrm{a}$ & $0,01 \mathrm{a}$ & $0,02 \mathrm{a}$ & $0,02 \mathrm{a}$ & 27,3 \\
DP $(\%)$ & $56,2 \mathrm{a}$ & $65,3 \mathrm{a}$ & $72,8 \mathrm{a}$ & $68,3 \mathrm{a}$ & 11,7 \\
DE $(2 \% / \mathrm{h})$ & $36,4 \mathrm{~b}$ & $35,2 \mathrm{~b}$ & $42,7 \mathrm{a}$ & $42,6 \mathrm{a}$ & 5,9 \\
DE $(5 \% / \mathrm{h})$ & $27,5 \mathrm{~b}$ & $27,2 \mathrm{~b}$ & $32,1 \mathrm{a}$ & $31,6 \mathrm{ab}$ & 5,8 \\
DE $(8 \% / \mathrm{h})$ & $23,9 \mathrm{~b}$ & $24,4 \mathrm{~b}$ & $28,1 \mathrm{a}$ & $27,2 \mathrm{ab}$ & 5,2 \\
\hline
\end{tabular}

SGE $=$ Silagem de grama estrela sem uso de aditivo SGE150 = Silagem de grama estrela com aditivo Katec $®$ Bacto Silo C. Tropical ( $150 \mathrm{~g}$ aditivo/ton de matéria natural); SGE300 = Silagem de grama estrela com aditivo Katec® Bacto Silo C. Tropical (300 g aditivo/ ton de matéria natural); SGEU = Silagem de grama estrela com uréia (10 kg/tonelada matéria natural). Médias seguidas por letras diferentes na mesma linha, diferem $(\mathrm{P}<0.05)$ pelo teste Tukey a $5 \%$ de probabilidade. 
A DP não apresentou diferenças significativas ( $\mathrm{P}>0,05)$, porém a diferença entre a silagem SGE300 e $\mathrm{SGE}$ chegou a 29,4\%. Este comportamento foi mantido para DE da matéria seca na taxa de passagem de $2 \%$ / h, que também teve seus maiores valores para os tratamentos SGE300 e SGEU. Na taxa de passagem de 5\% e 8\% a silagem SGE 300 manteve os maiores valores em relação aos tratamentos SGE150 e SGE, mas não em relação a SGEU.

Esses resultados são bastante próximos aos encontrados por Prado et al. (2004), estudando a degradabilidade de grama estrela e outras gramíneas sob pastejo contínuo no inverno e no verão. Também Santos et al. (1996) trabalhando com a cv. coastcross ensilada, registraram valores de $38,25 \%$ para a DE da MS com taxa de passagem de $2 \% / \mathrm{h}$.

As diferenças nos valores de DE podem ser explicadas pela aplicação do aditivo enzimobacteriano, que têm função de atuação na parede celular da forrageira ensilada. As maiores diferenças são observadas justamente na silagem SGE300, evidenciando que houve uma efetiva ação das enzimas no processo de degradação da parede celular. De acordo com Muck e Schinnes (2001), os produtos enzimáticos têm sido eficientes em alcançar o objetivo de degradação da parede celular.

Além do aditivo enzimo-bacteriano a uréia também mostrou-se efetiva, provavelmente atuando na solubilização de parte da parede celular. Segundo Harbes et al. (1982) a uréia, sendo hidrolisada e produzindo amônia pode resultar em efeito semelhante ao dos álcalis, expandindo a parede celular da planta após um período de armazenamento.

A Figura 1 apresenta o comportamento de desaparecimento de MS das silagens com diferentes aditivos. Observa-se pela Figura 1 a superioridade das silagens SGEU e SGE300, no desaparecimento da matéria seca das silagens. No entanto a silagem SGE mostrou-se superior em relação a SGE150. Esse comportamento é igual ao obtido para a degradabilidade efetiva da matéria seca, onde mostra que, as silagens SGE300 e SGEU foram superiores aos demais.

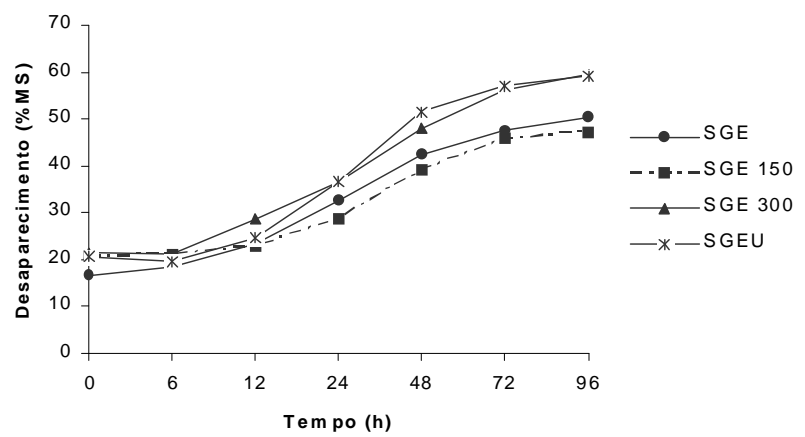

Figura 1. Curva de desaparecimento da matéria seca das silagens de grama estrela com diferentes aditivos.

SGE $=$ Silagem de grama estrela sem uso de aditivo; SGE150 = Silagem de grama estrela com aditivo Katec ${ }^{\circledR}$ Bacto Silo C. Tropical (150 g aditivo/ton de matéria natural); SGE300 = Silagem de grama estrela com aditivo Katec $®$ Bacto Silo C. Tropical (300 g aditivo/ton de matéria natural); SGEU = Silagem de grama estrela com uréia (10 kg/tonelada matéria natural).

O maior valor $(\mathrm{P}<0,05)$ encontrado para a fração solúvel (a) da PB foi para a silagem SGEU, mantendo o mesmo comportamento como para a degradabilidade da MS. A fração potencialmente degradável (b) não apresentou diferenças ( $\mathrm{P}>0,05)$, tendo valores muito próximos entre os tratamentos. Da mesma forma, a taxa de degradação também não mostrou diferenças significativas entre os valores.

A degradabilidade potencial da $P B$ não apresentou diferenças significativas $(\mathrm{P}>0,05)$, porém a silagem SGEU continuou mantendo os maiores valores $(7,2 \%)$ em relação ao valor obtido para a silagem SGE300.

Para a DE da PB a silagem SGEU apresentou os melhores resultados em todas as taxas de passagem $(2,5$ e $8 \% / h)$, enquanto que para as outras silagens observou-se valores bem próximos entre si, não alcançando níveis significativos. No entanto, os valores observados foram maiores do que os encontrados por Prado et al. (2004), estudando a degradabilidade da grama estrela sob pastejo contínuo. 
Tabela 3. Fração solúvel (a) e insolúvel potencialmente degradável (b), taxa de degradação (c), degradabilidade potencial (DP) e degradabilidade efetiva (DE) da Proteína Bruta das silagens para as taxas de passagem de $2 \% / \mathrm{h}, 5 \% / \mathrm{h}$ e $8 \% / \mathrm{h}$.

\begin{tabular}{lccccc}
\hline \multirow{2}{*}{ Parâmetros } & SGE & SGE150 & SGE300 & SGEU & CV\% \\
\cline { 2 - 6 } & \multicolumn{7}{c}{ Proteína Bruta } & $56,1 \mathrm{a}$ & 2,2 \\
\hline $\mathrm{a}$ & $60,5 \mathrm{~b}$ & $59,4 \mathrm{bc}$ & $56,1 \mathrm{c}$ & $22,4 \mathrm{a}$ & 18,7 \\
$\mathrm{~b}$ & $25,1 \mathrm{a}$ & $26,2 \mathrm{a}$ & $26,5 \mathrm{a}$ & $0,04 \mathrm{a}$ & 62,5 \\
$\mathrm{c}$ & $0,02 \mathrm{a}$ & $0,01 \mathrm{a}$ & $0,01 \mathrm{a}$ & $88,5 \mathrm{a}$ & 5,6 \\
$\mathrm{DP}(\%)$ & $85,7 \mathrm{a}$ & $85,7 \mathrm{a}$ & $82,6 \mathrm{a}$ & $80,9 \mathrm{a}$ & 1,2 \\
$\mathrm{DE}(2 \% / \mathrm{h})$ & $69,0 \mathrm{~b}$ & $70,0 \mathrm{~b}$ & $68,7 \mathrm{~b}$ & $76,2 \mathrm{a}$ & 1,7 \\
$\mathrm{DE}(5 \% / \mathrm{h})$ & $64,8 \mathrm{~b}$ & $65,0 \mathrm{~b}$ & $63,4 \mathrm{~b}$ & $73,8 \mathrm{a}$ & 1,9 \\
$\mathrm{DE}(8 \% / \mathrm{h})$ & $63,4 \mathrm{~b}$ & $63,2 \mathrm{~b}$ & $61,3 \mathrm{~b}$ & & \\
\hline
\end{tabular}

SGE $=$ Silagem de grama estrela sem uso de aditivo; SGE150 = Silagem de grama estrela com aditivo Katec® Bacto Silo C. Tropical ( $150 \mathrm{~g}$ aditivo/ton de matéria natural); SGE300 = Silagem de grama estrela com aditivo Katec $®$ Bacto Silo C. Tropical (300 g aditivo/ ton de matéria natural); SGEU = Silagem de grama estrela com uréia (10 kg/tonelada matéria natural).

Médias seguidas por letras diferentes na mesma linha, diferem $(\mathrm{P}<0.05)$ pelo teste Tukey a $5 \%$ de probabilidade.

O comportamento para a degradabilidade da $\mathrm{PB}$ pode ser explicado pelo efeito do teor de NNP da forragem pois, quando a uréia é adicionada a silagem, grande quantidade é hidrolisada à amônia durante a fermentação, observando-se aumentos nos teores de $\mathrm{PB}$ da silagem. Isso pode ser comprovado pela composição química das silagens (Tabela 1), em que o tratamento com aplicação de uréia apresenta valor próximo de $14 \%$ de proteína bruta, enquanto as outras silagens mostraram valores médios entre 8 e $10 \%$ de proteína. O comportamento do desaparecimento da PB pode ser visualizado (Figura 2).

Apesar de não apresentar diferença $(\mathrm{P}>0,05)$ na DP o tratamento com aplicação de uréia desponta com os maiores valores para a $\mathrm{DE}$, concordando com o comportamento da Figura 2, que mostra a superioridade deste no desaparecimento da proteína bruta em relação aos demais tratamentos.

Com relação à degradabilidade da FDN a silagem SGE300 apresentou os maiores valores para a fração solúvel (a) em relação as demais silagens, seguida da silagem SGE150 (8,66\%). As silagens com aplicação de inoculante apresentaram, no tempo zero, alta taxa de desaparecimento da fração FDN. A tendência de desaparecimento neste tempo é próxima de zero, o que evidencia que os valores obtidos podem estar relacionados a perdas ou contaminação do material durante o processo de incubação.

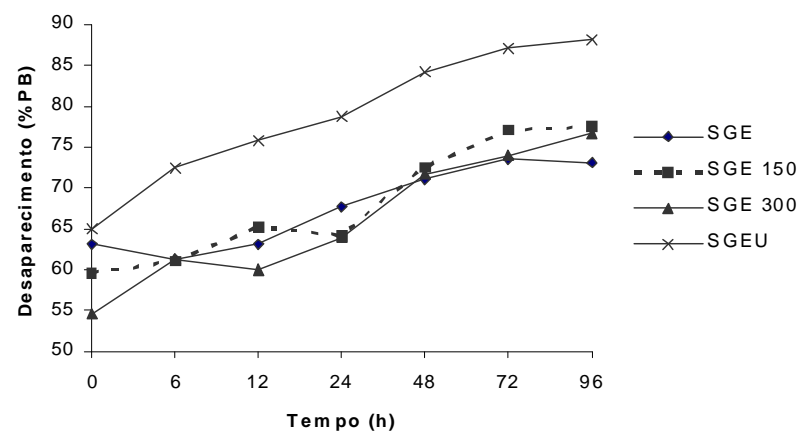

Figura 2. Curva de desaparecimento da proteína bruta das silagens de grama estrela com diferentes aditivos. $\mathrm{SGE}=$ Silagem de grama estrela sem uso de aditivo SGE150 = Silagem de grama estrela com aditivo Katec ${ }^{\circ}$ Bacto Silo C. Tropical (150 g aditivo/ton de matéria natural); SGE300 = Silagem de grama estrela com aditivo Katec ${ }^{\circledR}$ Bacto Silo C. Tropical (300 $\mathrm{g}$ aditivo/ton de matéria natural); $\mathrm{SGEU}=$ Silagem de grama estrela com uréia (10 kg/tonelada matéria natural).

Os valores da fração potencialmente degradável (b) não diferiram $(\mathrm{P}>0,05)$ entre si, porém os valores das silagens SGE300 e SGEU foram numericamente mais elevados, mostrando que a aplicação desses aditivos pode beneficiar a degradabilidade da fração FDN. Apesar de não significativa, devido a variações dos resultados confirmado pelo elevado coeficiente de variação, a diferença em percentuais entre a silagem SGE300 e SGE150, por exemplo, é de 53\% para a fração potencialmente degradável. 
Tabela 4. Fração solúvel (a) e insolúvel potencialmente degradável (b), taxa de degradação (c), degradabilidade potencial (DP) e degradabilidade efetiva (DE) da FDN das silagens para as taxas de passagem de $2 \% / \mathrm{h}, 5 \% / \mathrm{h}$ e $8 \% / \mathrm{h}$.

\begin{tabular}{lccccc}
\hline & \multicolumn{5}{c}{ Tratamentos } \\
\cline { 2 - 6 } Parâmetros & SGE & SGE150 & SGE300 & SGEU & CV\% \\
\hline a & $4,7 \mathrm{c}$ & $8,7 \mathrm{~b}$ & $12,7 \mathrm{a}$ & $3,3 \mathrm{c}$ & 20,4 \\
$\mathrm{~b}$ & $56,2 \mathrm{a}$ & $42,4 \mathrm{a}$ & $65,5 \mathrm{a}$ & $62,7 \mathrm{a}$ & 17,4 \\
$\mathrm{c}$ & $0,01 \mathrm{a}$ & $0,02 \mathrm{a}$ & $0,01 \mathrm{a}$ & $0,02 \mathrm{a}$ & 29,1 \\
$\mathrm{DP}(\%)$ & $60,9 \mathrm{ab}$ & $51,0 \mathrm{~b}$ & $78,2 \mathrm{a}$ & $65,9 \mathrm{ab}$ & 14,3 \\
$\mathrm{DE}(2 \% / \mathrm{h})$ & $28,3 \mathrm{~b}$ & $27,3 \mathrm{~b}$ & $38,6 \mathrm{a}$ & $34,3 \mathrm{ab}$ & 10,1 \\
$\mathrm{DE}(5 \% / \mathrm{h})$ & $17,3 \mathrm{~b}$ & $18,9 \mathrm{~b}$ & $26,4 \mathrm{a}$ & $21,1 \mathrm{ab}$ & 11,4 \\
$\mathrm{DE}(8 \% / \mathrm{h})$ & $13,3 \mathrm{~b}$ & $15,7 \mathrm{~b}$ & $22,0 \mathrm{a}$ & $15,8 \mathrm{~b}$ & 12,1 \\
\hline
\end{tabular}

$\mathrm{SGE}=$ Silagem de grama estrela sem uso de aditivo SGE150 = Silagem de grama estrela com aditivo Katec $®$ Bacto Silo C. Tropical ( $150 \mathrm{~g}$ aditivo/ton de matéria natural); SGE300 = Silagem de grama estrela com aditivo Katec ${ }^{\circledR}$ Bacto Silo C. Tropical (300 g aditivo/ ton de matéria natural); SGEU = Silagem de grama estrela com uréia (10 kg/tonelada matéria natural). Médias seguidas por letras diferentes na mesma linha, diferem $(\mathrm{P}<0.05)$ pelo teste Tukey a $5 \%$ de probabilidade.

Para esta análise estatística estipulou-se o valor de probabilidade de 5\% para diferença entre os valores, porém esses resultados só diferiram estatisticamente com probabilidade de $13 \%(\mathrm{P}<0,13)$. Os valores para o coeficiente de variação da FDN são os maiores em relação a MS e PB, podendo ter interferência nas discrepâncias de valores não significativos.

Não houve diferenças para a taxa de degradação (c), sendo observado o maior valor para o tratamento com aplicação de uréia $(0,021)$, onde se constatou elevado coeficiente de variação. Os valores observados estão coerentes com outras gramíneas do mesmo gênero registrados por Assis et al (1999), que avaliando Tifton 85 e Tifton 44 com 35 dias de período de corte, observou taxas de degradação de 0,028, aproximando-se dos valores obtidos neste estudo.

O tratamento SGE300 seguidos dos valores dos tratamentos SGEU e SGE resultaram nos maiores valores para a DP. O tratamento SGE150 foi o que apresentou o menor valor para a DP.

Para a DE os tratamentos SGE300 e o tratamento SGEU apresentaram valores superiores em relação aos demais tratamentos, mantendo uma média de $36,45 \%$ e $23,75 \%$ para taxa de passagem de 2 e $5 \%$ I $\mathrm{h}$ respectivamente, enquanto que para a taxa de passagem de $8 \% / \mathrm{h}$, o tratamento SGE300 foi superior $(22,03 \%)$ a todos os outros. Esse comportamento evidencia a atuação das enzimas presentes no inoculante de forma efetiva na degradação parcial da fibra, visto que, a DE para todas as taxas de passagem foram substancialmente maiores em relação aos outros tratamentos.

Valores próximos aos observados neste estudo foram encontrados para outras gramíneas do gênero Cynodon. Assis et al. (1999), avaliando a degradabilidade efetiva da fração FDN do capimTifton 85 cortado aos 35 dias, encontrou DE de $34,26 \%$ a uma taxa de passagem de $2 \%$ /h enquanto Reis (2000), observou valores de 33,86\% para a coastcross cortada aos 30 dias. Gonçalves (2001), observou para a grama Tifton 85, Tifton $44 \mathrm{e}$ coastcross valores médios de 31,0\% de DE da FDN para taxa de passagem de $2 \% / \mathrm{h}$. Malafaia et al. (1998) também relataram DE da FDN de 29,0\% para a grama Tifton- 85 , valores esses abaixo dos valores encontrados nesse estudo, porém obtidos com a gramínea sob pastejo.

A aplicação de aditivos e o próprio processo de fermentação atuam favoravelmente para que a degradação da parede celular seja facilitada em relação à forragem natural, visto que, a atuação de enzimas, a acidez do meio e atividade microbiológica colaboram (no sentido invasivo da fibra) para esse evento. O comportamento do desaparecimento da FDN pode ser visualizado na Figura 3. 
Na Figura 3 é visível o maior desaparecimento da FDN para silagem SGE300 e silagem SGEU, que também mostrou-se superior em relação a silagem SGE e também a silagem SGE 150. Esse comportamento é similar ao apresentado para a degradabilidade efetiva, que tem como maiores valores também os tratamentos SGE300 e o SGEU.

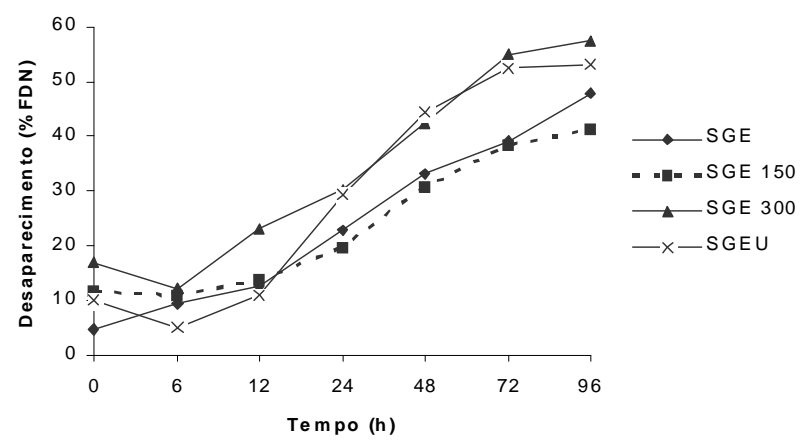

Figura 3. Curva de desaparecimento da fibra em detergente neutro das silagens de grama estrela com diferentes aditivos.

$\mathrm{SGE}=$ Silagem de grama estrela sem uso de aditivo SGE150 = Silagem de grama estrela com aditivo Katec ${ }^{\circledR}$ Bacto Silo C. Tropical (150 g aditivo/ton de matéria natural); SGE300 = Silagem de grama estrela com aditivo Katec ${ }^{\circledR}$ Bacto Silo C. Tropical (300 g aditivo/ton de matéria natural); SGEU = Silagem de grama estrela com uréia (10 kg/tonelada matéria natural).

Os dados obtidos para o fracionamento dos carboidratos das silagens de grama estrela estudadas são apresentados na Tabela 5. O maior valor para os carboidratos totais foi verificado na silagem SGE, seguida das silagens SGE300 e SGE150, enquanto a silagem SGEU apresentou o menor valor. O maior valor de carboidratos totais possivelmente tenha advindo das menores perdas e conseqüentemente também da menor fermentação, visto que, parte dos carboidratos é consumida nesse processo, ocasionando efeito de concentração.

Quanto a fração solúvel e rapidamente degradável $(A+B 1)$, os valores não mostraram diferença significativa, portanto não havendo influência dos aditivos. A justificativa para os valores da fração $\mathrm{A}+\mathrm{B} 1$ nos tratamentos com aditivo enzimo-bacteriano é que, possivelmente o consumo de carboidratos solúveis pelas bactérias no processo de fermentação possa ter influenciado a quantidade final desses no material ensilado, pelo motivo das enzimas disponibilizarem maiores quantidades de substrato para o processo de fermentação.

Porém, esse mecanismo de consumo de material solúvel pelas bactérias já era esperado, visto que, a produção de ácidos orgânicos é de fundamental importância para manter a qualidade de fermentação da silagem. Os ácidos orgânicos que são oriundos do metabolismo de carboidratos não são mensurados nesse fracionamento, porém são considerados altamente solúveis e disponíveis para o animal e microrganismos do rúmen.

Tabela 5. Fracionamento dos Carboidratos das silagens de grama estrela (Cynodon nlemfuensis Vanderyst.) com diferentes aditivos.

\begin{tabular}{lcccc}
\hline & \multicolumn{4}{c}{ Tratamentos } \\
\cline { 2 - 5 } & SGE & SGE150 & SGE300 & SGEU \\
\hline CHT (\% MS) & $84,2 \mathrm{a}$ & $83,0 \mathrm{~b}$ & $83,4 \mathrm{ab}$ & $81,4 \mathrm{c}$ \\
A+B1 (\% CHT) & $24,9 \mathrm{a}$ & $25,0 \mathrm{a}$ & $22,8 \mathrm{a}$ & $24,4 \mathrm{a}$ \\
B2 (\% CHT) & $55,3 \mathrm{a}$ & $55,6 \mathrm{a}$ & $58,5 \mathrm{a}$ & $54,5 \mathrm{a}$ \\
C (\% CHT) & $19,8 \mathrm{~b}$ & $19,3 \mathrm{bc}$ & $18,7 \mathrm{c}$ & $21,1 \mathrm{a}$ \\
\hline
\end{tabular}

SGE = Silagem de grama estrela sem uso de aditivo SGE150 = Silagem de grama estrela com aditivo Katec® Bacto Silo C. Tropical (150 g aditivo/ton de matéria natural); SGE300 = Silagem de grama estrela com aditivo Katec ${ }_{B}$ Bacto Silo C. Tropical (300 g aditivo/ton de matéria natural); SGEU = Silagem de grama estrela com uréia $(10 \mathrm{~kg} /$ tonelada matéria natural $)$. CHT $=$ Carboidratos totais; $\mathrm{A}+\mathrm{B} 1=$ Fração solúvel; B2 = Fibra potencialmente degradável; C = Fibra indigestível.

Médias seguidas por letras diferentes na mesma linha, diferem $(\mathrm{P}<0.05)$ pelo teste Tukey a $5 \%$ de probabilidade. 
A fração B2 também não apresentou diferença $(\mathrm{P}>0,05)$ entre tratamentos. Porém o maior valor numérico foi verificado para a silagem SGE300 $(58,48)$. Valores em torno de 53,0 e 58,0 foram observados por Backes et al. (2000) e Cabral et al. (1999), para a silagem de milho isenta de aditivos. A aplicação de aditivo (300 g/ton) apresentou valores semelhantes aos observados para a planta do milho, tradicionalmente ensilada e caracterizada pelo bom padrão de fermentação e digestibilidade. Esse dado pode dar maior respaldo em termos de qualidade da silagem de capim com aditivos, porém a dosagem deve ser comprovada como realmente efetiva.

Os menores valores para a fração $\mathrm{C}$ foram encontrados nas silagens com aplicação de inoculante. Isso provavelmente é decorrente da presença de enzimas no aditivo, que atua na degradação da fibra, melhorando sua qualidade. Por outro lado os maiores valores foram encontrados para a silagem SGEU e $\mathrm{SGE}$, no entanto, este não diferiu $(\mathrm{P}>0,05)$ da silagem SGE150.

\section{Conclusões}

A aplicação do dobro da dosagem recomendada do inoculante (300 g/tonelada) melhorou a degradabilidade efetiva da MS e da FDN da silagem de grama estrela, enquanto o tratamento com uréia melhorou a degradabilidade efetiva da fração proteína bruta.

A silagem de grama estrela com uso do dobro da dosagem de inoculante enzimo-bacteriano recomendada pelo fabricante, mostraram menor fração indigestível no fracionamento de carboidratos em relação a silagem sem aditivo ou com adição de uréia.

\section{Referências}

AGRICULTURAL AND FOOD RESEARCH COUNCIL AFRC. Energy and protein requirements of ruminant. Wallingford, UK: CAB International, 1993.

ASSIS, M. A.; SANTOS, G. T.; CECATO, U.; DAMASCENO, J. C.; PETIT, H. V.; BETT, W.; GOMES, L. H.; DANIEL, M. Degradabilidade in situ de gramíneas do gênero Cynodon submetidas ou não a adubação nitrogenada. Acta Scientiarum, Maringá, v.21, n.3, p.657663, 1999.

ASSOCIATION OF OFFICIAL ANALITICAL CHEMISTS - AOAC. Official methods of analysis. 12.ed. Washington. D.C.: AOAC, 1985.

BACKES, A. A.; SANCHEZ, L. M. B.; GONÇALVES, M. B. F.; VELHO, J. P. Determinação das frações de proteína e carboidratos de alguns alimentos conforme método de CNCPS. In: REUNIÃO ANUAL DA SOCIEDADE BRASILEIRA DE ZOOTECNIA, 37., 2000, Viçosa. Anais...Viçosa: SBZ, 2000. p.913-915.

CABRAL, L. S.; VALADARES FILHO, S. C.; MALAFAIA, P. A. M.; LANA, R. P.; SILVA, J. F. C.; VIEIRA, R. A. M. Frações de carboidratos de volumosos tropicais e suas taxas de degradação estimadas através das técnicas de produção de gases. In: REUNIÃO ANUAL DA SOCIEDADE BRASILEIRA DEZOOTECNIA, 36., 1999, Porto Alegre. Anais... Porto Alegre: SBZ, 1999. p.121.

GARCIA, J.; ALCALDE, C. R.; JOBIM, C. C.; ZAMBOM, M. A.; DAMASCENO, J. C.; SANTOS, V. C. Degradabilidade in situ de alimentos concentrados e do capim Brachiaria decumbens Stapf. em diferentes crescimentos vegetativos. Acta Scientiarum, Maringá, v.25, n.2, p.387-395, 2003.

GONÇALVES, G. D. Avaliação nutricional de gramíneas do gênero Cynodon, 2001. Dissertação (Mestrado em Zootecnia) - Universidade Estadual de Maringá, Maringá.

HARBERS, L. H.; KREITNER, G. L.; DAVIS, Jr. G.; RASMUSSEN, M. A.; CORAH, L. R. Ruminal hidroxide treated wheat straw observed by seaning eletron microscopy. Journal Animal. Science. 54(6):1309-1319, 1982.

MALAFAIA, P. A. M.; VALADARES FILHO, S. C.; VIEIRA, R. A. M.; SILVA, J. F. C.; PEREIRA, J. C. Determinação das frações que constituem os carboidratos totais e da cinética ruminal da fibra em detergente neutro de alguns alimentos para ruminantes. Revista Brasileira de Zootecnia, Viçosa, v.27, n.4, p.790-796, 1998.

MEHREZ. A. Z.; ORSKOV, E. R. A study of the artificial fiber bag tecnique for determining the digestibility of feeds in the rumen. Journal of Agriculture Science, Cambridge, v.88, n.1, p.6450-6550, 1977.

MINSON, D. J. Forrage in ruminat nutrition. San Diego: Academic Press, 1990.

MUCK, R. E.; SCHINNES, K. J. Conserved forages (silage and hay): progress and priorities. In: INTERNATIONAL GRASSLAND CONGRESS, 19., 2001, São Pedro. Proceedings... Piracicaba: Brazilian Society of Animal Husbandry, 2001. p.753-762. 
NUTRITIONAL RESEARCH COUNCIL - NRC. Nutrient requirements of beef cattle. 7.ed. Washington, D.C.: National Academy of Science, 1996.

ORSKOV, E. R.; McDONALD, I. The estimation of protein degradability in the rumen from incubation measurements weighted according to rate of passage. Journal of Agriculture Science, Cambridge, v.92, n.2, p.499-504, 1979.

PRADO, I. N.; MOREIRA, F. B.; ZEOULA, L. M.; WADA, F. Y.; MIZUBUTI, I. Y.; NEVES, C. A. Degradabilidade in situ da matéria seca, proteína bruta e fibra em detergente neutro de algumas gramíneas sob pastejo contínuo. Revista Brasileira de Zootecnia, Viçosa, v.33, n.5, p.13321339, 2004.

REIS, R. A.; BERNARDES, T. F.; SIQUEIRA, G. R. Tecnologia de produção e valor alimentício de silagens de capins tropicais. In: SIMPÓSIO SOBRE PRODUÇÃO E UTILIZAÇÃO DE FORRAGENS CONSERVADAS, 2 ., 2004, Maringá. Anais... Maringá, UEM, 2004. p.34-74.

REIS, S. T. Valor nutricional de gramíneas tropicais em diferentes idades de corte, 2000. Dissertação (Mestrado em Zootecnia) - Universidade Federal de Lavras, Lavras.
SANTOS, G. T.; PETIT, H. V.; CECATO, U.; OLIVEIRA, R. L.; ZEOULA, L. M.; RIGOLON, L. P.; DASMACENO, J. C.; BETT, W. Efeito do ácido tânico sobre a proteólise no silo e a degradabilidade ruminal das silagens de coastcross (Cynodon dactylon L. Pers) e alfafa (Medicago sativa L.). In: REUNIÃO ANUAL DA SOCIEDADE BRASILEIRA DE ZOOTECNIA, 33., 1996, Fortaleza. Anais... Fortaleza: SBZ, 1996. p.350-352.

SNIFFEN, C. J.; O'CONNOR, J. D.; VAN SOEST, P. J.; FOX, D. G.; RUSSELL, J. B. A net carbohydrate and protein system for evaluating cattle diets II. Carbohydrate and protein availability. Journal of Animal Science, Champaign, v.70, n.11, p.3562-3577, 1992.

UNIVERSIDADE FEDERAL DE VIÇOSA. S.A.E.G: Sistema para análises estatísticas e genéticas. Versão 7.1. Viçosa: Editora UFV, 1997. (Manual do usuário).

VAN SOEST, P. J.; ROBERTSON, J. B.; LEWIS, B. A. Methods for dietary fiber, neutral detergent fiber, and nonstarch polysaccharides in relation to animal nutrition. Journal of Dairy Science, Champaign, v.74, n.12, p.3583$3597,1991$. 
